\title{
Myeloid A Disintegrin and Metalloproteinase Domain 10 Deficiency Modulates Atherosclerotic Plaque Composition by Shifting the Balance from Inflammation toward Fibrosis
}

Emiel P.C. van der Vorst, ${ }^{* \dagger}$ Mike Jeurissen, ${ }^{*}$ Ine M.J. Wolfs, ${ }^{\dagger}$ Anke Keijbeck, ${ }^{*}$ Kosta Theodorou ${ }^{\dagger}$ Erwin Wijnands, Leon Schurgers, ${ }^{\ddagger}$ Silvio Weber, ${ }^{\S \uparrow \|}$ Marion J. Gijbels, ${ }^{* \dagger * *}$ Anouk A.J. Hamers, ${ }^{* *}$ Daniela Dreymueller, ${ }^{\dagger \dagger}$ Stefan Rose-John, Menno P.J. de Winther, ${ }^{* *}$ Andreas Ludwig, ${ }^{\dagger \dagger}$ Paul Saftig, ${ }^{\S}$ Erik A.L. Biessen, ${ }^{\dagger}$ and Marjo M.P.C. Donners ${ }^{* \dagger}$

From the Departments of Molecular Genetics, * Pathology, ${ }^{\dagger}$ and Biochemistry, ${ }^{\ddagger}$ Cardiovascular Research Institute Maastricht, Maastricht University, Maastricht, the Netherlands; the Institute for Biochemistry, ${ }^{\S}$ Christian-Albrechts-University, Kiel, Germany; the Heart Research Centre Göttingen, ${ }^{\natural}$ and the Department of Cardiology and Pneumology, University Göttingen, Göttingen, Germany; the Department of Pharmacology and Toxicology, "Medical Faculty Carl Gustav Carus, Dresden University of Technology, Dresden, Germany; the Department of Medical Biochemistry, ** Academic Medical Center Amsterdam, Amsterdam, the Netherlands; and the Institute for Pharmacology and Toxicology, ${ }^{\dagger \dagger}$ Rheinisch-Westfälische Technische Hochschule Aachen University, Aachen, Germany

Accepted for publication November 25, 2014.

Address correspondence to Marjo M.P.C. Donners, Ph.D., Cardiovascular Research Institute Maastricht, Maastricht University, Universiteitssingel 50, 6229 ER Maastricht, the Netherlands. E-mail: marjo. donners@maastrichtuniversity.nl.

\begin{abstract}
A disintegrin and metalloproteinase domain 10 (ADAM10) is a metalloprotease involved in cleavage of various cell surface molecules, such as adhesion molecules, chemokines, and growth factor receptors. Although we have previously shown an association of ADAM10 expression with atherosclerotic plaque progression, a causal role of ADAM10 in atherosclerosis has not been investigated. Bone marrow from conditional knockout mice lacking Adam10 in the myeloid lineage or from littermate controls was transplanted into lethally irradiated low density lipoprotein receptor $\mathrm{Ldlr}^{-/-}$mice on an atherogenic diet. Myeloid Adam10 deficiency did not affect plaque size, but it increased plaque collagen content. Matrix metalloproteinase 9 and 13 expression and matrix metalloproteinase 2 gelatinase activity were significantly impaired in Adam10-deficient macrophages, whereas their capacity to stimulate collagen production was unchanged. Furthermore, relative macrophage content in advanced atherosclerotic lesions was decreased. In vitro, Adam10-deficient macrophages showed reduced migration toward monocyte chemoattractant protein-1 and transmigration through collagen. In addition, Adam10-deficient macrophages displayed increased anti-inflammatory phenotype with elevated IL-10, and reduced production of proinflammatory tumor necrosis factor, IL-12, and nitric oxide in response to lipopolysaccharide. These data suggest a critical role of Adam10 for leukocyte recruitment, inflammatory mediator production, and extracellular matrix degradation. Thereby, myeloid ADAM10 may play a causal role in modulating atherosclerotic plaque stability. (Am J Pathol 2015, 185: 1145-1155; http://dx.doi.org/10.1016/j.ajpath.2014.11.028)
\end{abstract}

A disintegrin and metalloproteinase domain 10 (ADAM10) is a ubiquitously expressed enzyme that can cleave extracellular domains of various cell surface molecules (a process called shedding), such as adhesion molecules, cytokines/chemokines, and growth factor receptors. ADAM10-mediated cleavage of specific substrates has been associated with various diseases, ranging from a protective function in Alzheimer disease to a detrimental role in rheumatoid arthritis and cancer. ${ }^{1,2}$ A crucial role for ADAM10 in the development of the cardiovascular system is evident from the embryonic lethality of classic Adam $10^{-1-}$ mice, which were seen to display overt cardiac and vascular malformations. ${ }^{3}$ Conditional deletion of Adam10 in endothelial cells resulted in either embryonic lethality ${ }^{4}$ or viable

Supported by the Netherlands Heart Foundation Dr. E. Dekker postdoctoral grants 2007T034 and 2012T079 (M.M.P.C.D.) and the Deutsche Forschungsgemeinschaft grant SFB877-TPA3 (P.S. and S.W.).

Disclosures: None declared. 
mice with vascular abnormalities and increased pathological neovascularization in a model of oxygen-induced retinopathy. ${ }^{5}$ In agreement, we previously showed an important role of ADAM10 in vascular endothelial growth factor-induced endothelial cell functions (eg, regulation of vascular permeability by cleaving vascular endothelial cadherin and migration of both endothelial cells and monocytes). ${ }^{6}$ These processes are not only critically involved in angiogenesis, but also in atherosclerosis, the main underlying pathological feature of cardiovascular diseases.

Atherosclerosis is a chronic inflammatory disease characterized by the accumulation of lipids, extracellular matrix, and inflammatory cells in the vessel wall. Although ADAM10 is implicated in various processes that are crucially involved in atherosclerosis, ${ }^{7}$ such as leukocyte adhesion and transmigration, the causal role of ADAM10 in cardiovascular diseases has not been investigated. Interestingly, we were the first to demonstrate ADAM10 expression in human atherosclerotic lesions, associated with plaque neovascularization and disease progression. ${ }^{6}$ In addition to neovascularization, the progression and stability of atherosclerotic lesions are strongly influenced by the balance between proinflammatory and anti-inflammatory cytokines, thereby determining clinical outcome. ${ }^{8}$ In the atherosclerotic plaque, macrophages are the predominant inflammatory cell type and crucial determinants of the inflammatory equilibrium. ${ }^{9}$ Because we found high expression of ADAM10 in plaque macrophages, ${ }^{6}$ we hypothesize that macrophage ADAM10 is crucially involved in inducing plaque development and progression.

Herein, we examined the role of Adam10 in atherosclerotic plaque development by crossing Adam10-floxed mice with the lysozyme $\mathrm{M}$ (LysM)-cre-deleter $\operatorname{strain}^{10}$ to induce a myeloid-specific deletion of Adam10. Transplantation of Adam10-LysMcre bone marrow into atherogenic low density lipoprotein receptor $\mathrm{Ldlr}^{-1-}$ mice showed that, although total plaque size was not affected, myeloid Adam10 deficiency increased features of atherosclerotic plaque stability in these mice by increasing collagen and decreasing macrophage content of plaques.

\section{Materials and Methods}

\section{Generation and Characterization of} Adam $10^{f l / f l}$ LysM-cre ${ }^{+/ 0}$ Mice

The Adam $10^{f l o x f f o x}$ mice $^{11}$ were generously donated by Paul Saftig (Kiel University, Germany), crossed with LysM-cre mice, ${ }^{10}$ and backcrossed to a C57Bl6 background for at least six generations. Mice were analyzed both macroscopically and microscopically for general organ morphological features, including lungs, heart, gastrointestinal tract, liver, pancreas, brain, skin, urinary and reproductive systems, spleen, lymph nodes, thymus, thyroid, and salivary and adrenal glands. For all experiments, we compared Adam $10^{\nexists / f}$ LysM-cre ${ }^{+/ 0}$ mice (indicated as ADAM10 $0^{\mathrm{del}}$ ) to age- and sex-matched Adam $10^{f / f l}$ LysM-cre $^{0 / 0}$ littermate controls (ADAM10 ${ }^{\mathrm{wt}}$ ).
Table 1 List of Antibodies Used for Flow Cytometry

\begin{tabular}{lll}
\hline Antigen & Clone & Company \\
\hline CD16/32 & 93 & eBioscience (Vienna, Austria) \\
CD45 & $30-$ F11 & Biolegend (Uithoorn, the Netherlands) \\
CD3e & $145-2 c 11$ & eBioscience \\
NK1.1 & PK136 & BD \\
Ly6G & 1 A8 & BD \\
CD11b & M1/70 & BD \\
Ly6C & $1 G 7.610$ & Miltenji (Leiden, the Netherlands) \\
CD4 & GK1.5 & BD \\
CD8 & $53-6.7$ & eBioscience \\
CD25 & PC61.5 & eBioscience \\
Foxp3 & FJK-16s & eBioscience \\
B220 & RA3-6B2 & BD \\
F4/80 & CI:A31 & AbD (Puchenheim, Germany) \\
CD19 & $1 D 3$ & eBioscience \\
IL10 & Jes5-16E3 & eBioscience \\
IL12 & C17.8 & eBioscience \\
ADAM10 & 139712 & R\&D Systems (Minneapolis, USA) \\
\hline
\end{tabular}

ADAM, a disintegrin and metalloproteinase domain.

All animal experiments were approved by the Animal Ethics Committee of the Maastricht University (Maastricht, the Netherlands; permit number 2008-017).

\section{Bone Marrow-Derived Macrophage Isolation and Culture}

Bone marrow cells were isolated from femurs and tibiae of either wild-type or ADAM10 ${ }^{\text {del }}$ mice. Cells were cultured in RPMI 1640 medium (GIBCO Invitrogen, Breda, the Netherlands) with $10 \%$ heat-inactivated fetal calf serum (Bodinco B.V., Alkmaar, the Netherlands), $100 \mathrm{U} / \mathrm{mL}$ penicillin, $100 \mu \mathrm{g} / \mathrm{mL}$ streptomycin, and $2 \mathrm{mmol} / \mathrm{L}$ L-glutamine (all from GIBCO Invitrogen), supplemented with 15\% L929conditioned medium for 8 to 9 days to generate bone marrow-derived macrophages, as described previously. ${ }^{12}$

Macrophages were seeded at 350,000 cells per well in 24-well plates and incubated for 6 to 24 hours with 0 to 10 $\mathrm{ng} / \mathrm{mL}$ lipopolysaccharide (LPS) or 0 to $25 \mu \mathrm{g} / \mathrm{mL} \mathrm{CuSO}_{4}$ oxidized low-density lipoprotein (oxLDL) for 24 hours. Enzyme-linked immunosorbent assays (all from Invitrogen) for Il-12, Il-10, and tumor necrosis factor $\alpha$ (Tnf- $\alpha$ ) were performed on conditioned medium, according to the manufacturer's instructions. Analysis was performed using a microplate reader (Bio-Rad, Veenendaal, the Netherlands) at $450 \mathrm{~nm}$. Nitric oxide (NO) production was measured in conditioned medium using Griess reagent $\left(2.5 \% \mathrm{H}_{3} \mathrm{PO}_{4}, 1 \%\right.$ sulfanilamide, and $0.1 \%$ naphthalene diamine dihydrochloride). Analysis was performed using a microplate reader (Bio-Rad) at $550 \mathrm{~nm}$.

\section{Western Blot Analysis}

Cell pellets of bone marrow-derived macrophages from $\mathrm{ADAM} 10^{\mathrm{wt}}$ and ADAM10 ${ }^{\mathrm{del}}$ mice were resuspended and homogenized in equal volumes of lysis buffer (1\% Triton 
Table 2 List of Primer Sequences

\begin{tabular}{|c|c|c|}
\hline Primer name & Forward primer & Reverse primer \\
\hline Adam10 genomic & 5'-TACAACCATGCCCAGCTTTTTAGT-3' & $5^{\prime}$-GCCGATGTGCCAGATGAGTG-3' \\
\hline PCR qPCR & $5^{\prime}$-AGCAACATCTGGGGACAAAC - 3' & $5^{\prime}-\mathrm{TTGCACTGGTCACTGTAGCC-3^{ \prime }}$ \\
\hline Adam17 & $5^{\prime}$-GTACGTCGATGCAGAGCAAA-3' & 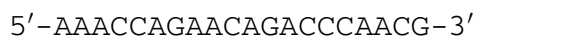 \\
\hline Cyclophilin & 5'-ТTССТССТTТСАСАGААТTАТTССА-3' & 5'-CCGCCAGTGCCATTATGG-3' \\
\hline$\beta$-Actin & 5'-GACAGGATGCAGAAGGAGATTACTG-3' & $5^{\prime}$-CCACCGATCCACACAGAGTACTT-3' \\
\hline GAPDH & 5'-CAACTCACTCAAGATTGTCAGCAA-3' & $5^{\prime}-$ TGGCAGTGATGGCATGGA-3' \\
\hline Collagen I & $5^{\prime}-\mathrm{AACCCTGCCCGCACATG}-3^{\prime}$ & $5^{\prime}$-CAGACGGCTGAGTAGGGAACA- $3^{\prime}$ \\
\hline Collagen III & 5'-GGGATCAAATGAAGGCGAATT-3' & 5'-CAAAGACTGTCTTGCTCCATTCC-3' \\
\hline Collagen IV & 5'-GGAGTCTCTGGATTGGGTACTCA-3' & $5^{\prime}-$ CGAACGGTGCAGCTCTGAA- $3^{\prime}$ \\
\hline Collagen VIII & $5^{\prime}-$ TGGGCAAAGATGGCCTTTC-3' & $5^{\prime}-\mathrm{CCGCGCAAACTGGCTAA-3^{ \prime }}$ \\
\hline Mmp-2 & $5^{\prime}$-AGACATACATCTTTGCAGGAGACAAG-3' & $5^{\prime}-$ TGAGCTTAGGGAAACCGGG-3' \\
\hline
\end{tabular}

ADAM, a disintegrin and metalloproteinase domain; GAPDH, glyceraldehyde-3-phosphate dehydrogenase; Mmp, matrix metalloproteinase; qPCR, real-time quantitative PCR; TGF, transforming growth factor.

$\mathrm{X}-100$, protease inhibitor, $150 \mathrm{mmol} / \mathrm{L} \mathrm{NaCl}, 200 \mathrm{mmol} / \mathrm{L}$ Tris, and glycerol). Equal amounts of protein were separated by $10 \%$ SDS-PAGE and transferred to a nitrocellulose membrane. Membranes were probed with primary antiAdam10 antibody (1:500; a generous gift from Stefan Rose-John, Kiel University, Germany), followed by secondary donkey anti-rabbit-peroxidase $(1: 10,000)$ antibody. Chemiluminescence was detected using a digital scanner.

\section{Bone Marrow Transplantation}

Male ADAM10 ${ }^{\mathrm{del}}$ or ADAM10 ${ }^{\mathrm{wt}}$ mice (aged 10 to 12 weeks) were used as donor mice ( $n=5$ per group). Forty female $\mathrm{Ldlr}^{-/-}$recipient mice (10 to 12 weeks old), backcrossed onto a C57B16 background for $>10$ generations, were obtained from in-house breeding. Bone marrow transplantations were performed as described elsewhere. ${ }^{13}$ In short, $\mathrm{Ldlr}^{-/-}$mice were lethally irradiated with 6 Gy a day before and on the day of transplantation. Mice were transplanted with $5 \times 10^{6}$ bone marrow cells isolated from wild-type or ADAM $10^{\text {del }}$ mice. After recovery for 5 weeks after transplantation, mice were given a Western-type diet (WTD), containing $16 \%$ fat and $0.15 \%$ cholesterol (Hope Farms, Woerden, the Netherlands). Before WTD feeding, mice were fasted for 4 hours, after which blood samples were drawn from the tail vein for analysis of plasma lipids and chimerism. Additional blood analysis was performed at 5 and 10 weeks of WTD. The chimerism in transplanted mice was determined on DNA from blood leukocytes, as described previously. ${ }^{13}$

\section{Morphometry and Immunohistochemistry of Murine Tissues}

After 10 weeks of WTD feeding, mice were anesthetized and euthanized. Mouse hearts were dissected and snap frozen in optimal cutting temperature. Atherosclerosis development (lesion size and progression stage) was determined as previously described, ${ }^{14}$ with a slight modification in plaque classification. Plaques were classified as early (foam cell rich, but lacking a necrotic core), moderately advanced (containing a fibrotic cap and often a necrotic core, but no medial macrophage infiltration), and advanced lesions, typified by medial macrophage infiltrates, elastic lamina degradation, and more pronounced necrosis and fibrosis. Serial sections ( $7 \mu \mathrm{m}$ thick) of the aortic root were cut and stained with toluidine blue for morphometric analysis and routine qualitative examination of collagen content, necrosis, foam cell content, and amount of inflammatory cells [using scores from 0 (absent) to 3 (high abundance)]. Moma2 (an antibody recognizing monocytes/macrophages; a gift from George Kraal, VU University Medical Center, Amsterdam, the Netherlands), NIMP-1 (in-house cultured and purified antibody against neutrophils), terminal deoxynucleotidyl transferase-mediated dUTP nick-end labeling (TUNEL; Roche Diagnostics, Mannheim, Germany), and Sirius Red staining were used for the detection of monocytes/macrophages, neutrophils, apoptotic cells, and collagen, respectively. Supplemental Figure S1 illustrates the region of interest used in all our plaque analyses, distinguishing plaque from media and aortic valve leaflets. A polarization filter and birefringence color discrimination were used to differentiate various collagen structures (ranging from loosely patched, immature, thin collagen to tightly packed, mature, thick collagen fibers), as described by MacKenna et al. ${ }^{15}$

\section{Lipid Analysis}

Mice were fasted for 4 hours, before blood was drawn for plasma lipid analyses. Total plasma cholesterol and triglyceride levels and cholesterol in lipoprotein fractions were determined using standard enzymatic kits, according to the 

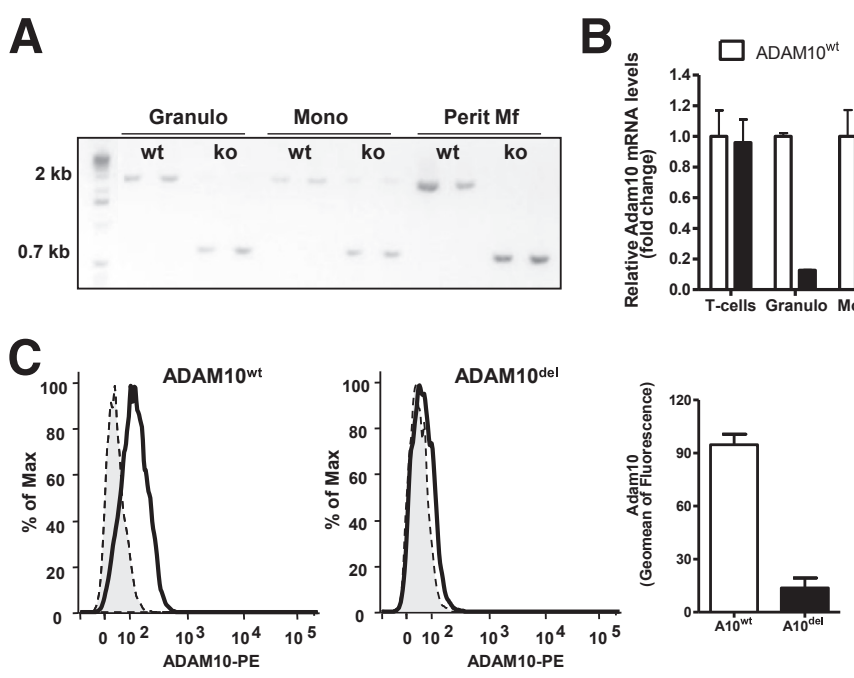

manufacturer's protocols (Sigma-Aldrich, Zwijndrecht, the Netherlands).

\section{Flow Cytometry Analysis (Fluorescence-Activated Cell Sorting)}

Absolute circulating leukocyte subset numbers were determined by flow cytometry calibrated using Trucount Beads (BD, Franklin Lakes, NJ). Leukocytes were defined as $\mathrm{CD}_{4}{ }^{+}$, $\mathrm{T}$ cells as $\mathrm{CD} 45^{+} \mathrm{CD}^{+}{ }^{-} \mathrm{NK} 1.1^{-}$, natural killer (NK) cells as $\mathrm{CD}_{4} 5^{+} \mathrm{CD}^{-}{ }^{-} \mathrm{NK} 1.1^{+}, \mathrm{B}$ cells as $\mathrm{CD} 45^{+}$ $\mathrm{CD}^{-} \mathrm{NK}^{-} 1^{-} \mathrm{B} 220^{+}$, granulocytes as $\mathrm{CD}^{-} 5^{+} \mathrm{CD}^{-}$ $\mathrm{NK} 1.1^{-} \mathrm{B} 220^{-} \mathrm{CD}^{-11 b^{+}} \mathrm{Ly}_{6 G^{+}}$, and monocytes as $\mathrm{CD}^{+} 5^{+}$ $\mathrm{CD}^{-}{ }^{-} \mathrm{NK} 1.1^{-} \mathrm{B} 220^{-} \mathrm{CD}^{-11 b^{+}} \mathrm{Ly}^{-} \mathrm{G}^{-}$. Inflammatory and resident monocytes were defined as $\mathrm{Ly} 6 \mathrm{C}^{\text {high }}$ and $\mathrm{Ly} 6 \mathrm{C}^{-}$, respectively, T-helper cells as $\mathrm{CD} 45^{+} \mathrm{CD} 3^{+} \mathrm{CD} 4^{+}$, cytotoxic $\mathrm{T}$ cells as $\mathrm{CD} 45^{+} \mathrm{CD} 3^{+} \mathrm{CD} 8^{+}$, and regulatory $\mathrm{T}$ cells as $\mathrm{CD}^{+} \mathrm{CD}^{+} \mathrm{CD}^{+} 5^{+} \mathrm{Foxp}^{+}$. As a measure of peritoneal macrophage polarity, intracellular IL-10 and IL-12 production was assessed by flow cytometry, 6 hours after activation by $10 \mathrm{ng} / \mathrm{mL}$ LPS in the presence of GolgiSTOP (1:2000; BD-Pharmingen, Breda, the Netherlands) and subsequent permeabilization. $\mathrm{CD}^{-} 9^{-} \mathrm{F} 4 / 80^{+}$cells were considered macrophages. Adam 10 cell surface expression levels on bone marrow-derived macrophages (BMDMs) were measured by flow cytometry and expressed as geomean fluorescence intensity. A list of applied antibodies is given in Table 1.

\section{Vascular SMC Isolation and Culture}

Primary mouse vascular smooth muscle cells (SMCs) were isolated by collagenase and elastase (both from SigmaAldrich) digestion of freshly dissected C57B16 mouse aortas. Cells were cultured on $1 \mathrm{mg} / \mathrm{mL}$ laminin-coated wells (Sigma-Aldrich) in Dulbecco's modified Eagle's medium (GIBCO Invitrogen) with 10\% heat-inactivated fetal calf serum (Bodinco B.V.), $100 \mathrm{U} / \mathrm{mL}$ penicillin, 100 $\mu \mathrm{g} / \mathrm{mL}$ streptomycin, and $2 \mathrm{mmol} / \mathrm{L} \mathrm{L}$-glutamine (all from
Figure 1 A: Genomic PCR of Adam10 (wild type, $2 \mathrm{~kb}$; knockout, $0.7 \mathrm{~kb}$ ) constructs in the spleen granulocytes (Granulo), monocytes (Mono), and peritoneal macrophages (Perit Mf). B: Adam10 mRNA expression in peritoneal macrophages, bone marrow-derived macrophages (BMDMs), and circulating granulocytes, monocytes, and T cells of $\operatorname{ADAM}^{\mathrm{wt}}\left(\mathrm{A} 10^{\mathrm{wt}}\right)$ and ADAM10 ${ }^{\text {del }}\left(\mathrm{A} 10^{\mathrm{del}}\right)$ mice [isolated by fluorescence-activated cell sorting (FACS) sorting]. C: FACS analysis of Adam10 (black line) or isotype control (dotted line) in BMDMs and D: Soluble CXCL16 levels in unstimulated BMDM supernatant. $n=2$ per group (B); $\mathrm{n}=3$ per group (C); $\mathrm{n}=6$ per group (D). ${ }^{*} P<0.01$.

GIBCO Invitrogen). Cells were used for experiment between passages 6 and 8 .

\section{Collagen Assay in Vascular SMCs}

SMCs were plated as 50,000 cells per well. After overnight attachment, cells were starved ( $0 \%$ fetal calf serum) for 48 hours and then incubated with macrophage supernatants for 24 hours. Collagen production was measured by fixating the cells in $3.7 \%$ formaldehyde, staining with $1 \%$ Sirius Red in $0.01 \mathrm{~mol} / \mathrm{L} \mathrm{HCl}$, and lysing with $0.01 \mathrm{~mol} / \mathrm{L} \mathrm{NaOH}$, as described previously. ${ }^{16}$ Analysis was performed using a microplate reader (Bio-Rad) at $544 \mathrm{~nm}$, using a gelatin standard.

\section{Gene Expression}

RNA was isolated with the High Pure RNA Isolation Kit (Roche, Basel, Switzerland). RNA (500 ng total) was reverse transcribed using the iScript cDNA Synthesis Kit
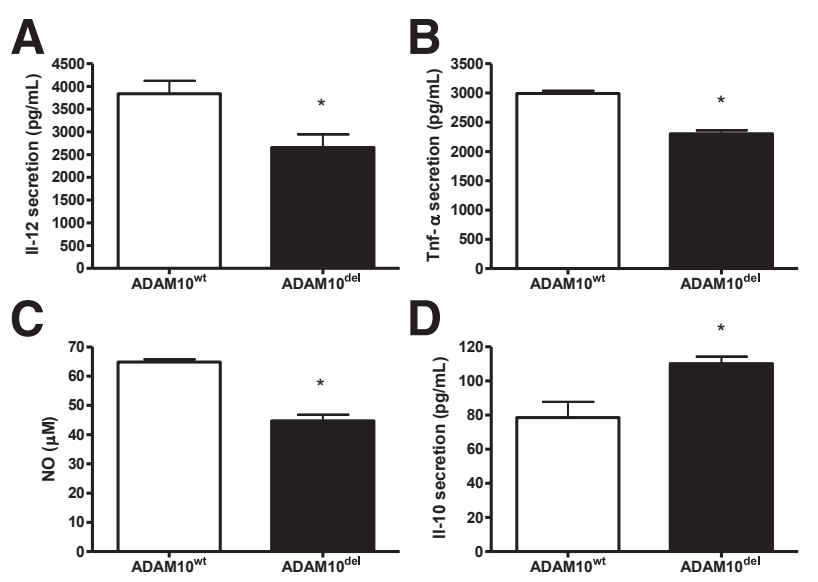

Figure 2 Proinflammatory mediator $(\mathbf{A}-\mathbf{C})$ and anti-inflammatory cytokine (D) production by bone marrow-derived macrophage activation by lipopolysaccharide [ 6 hours for tumor necrosis factor (Tnf) and Il-10; 24 hours for Il-12 and nitric oxide (NO)] $n=3$ per group. ${ }^{*} P<0.05$. 
A

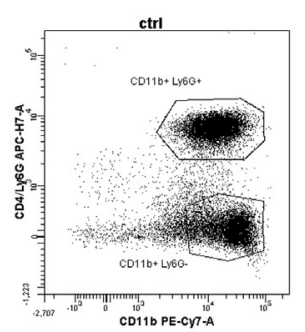

ADAM10wt

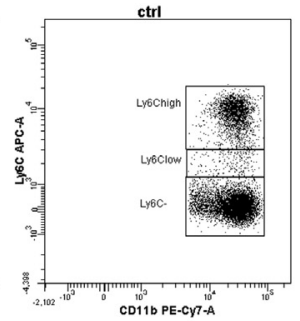

B

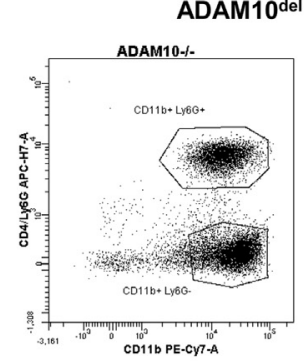

$\mathbf{F}$

E

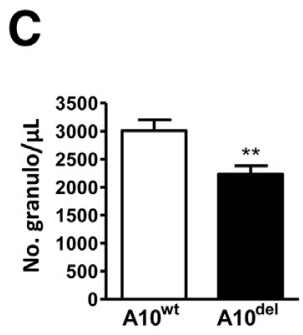

D
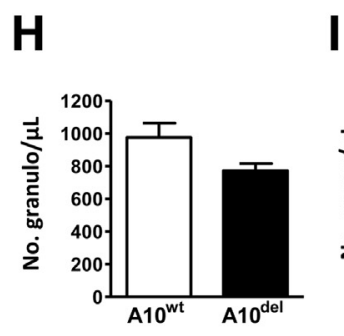
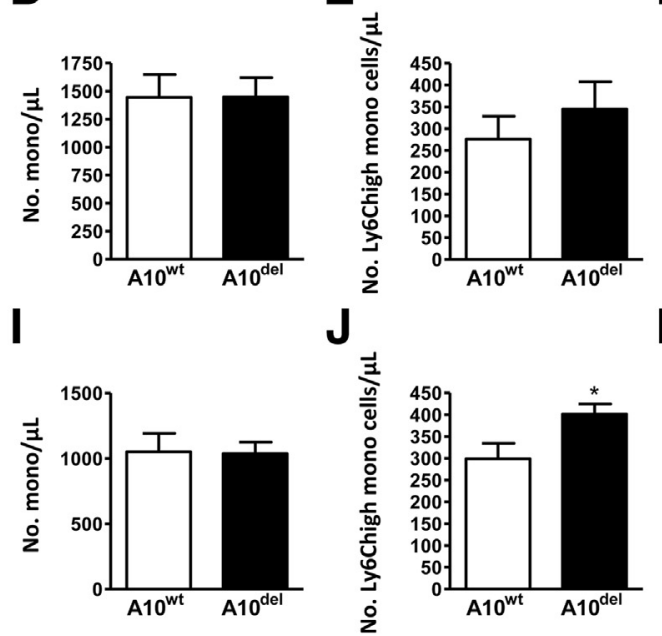

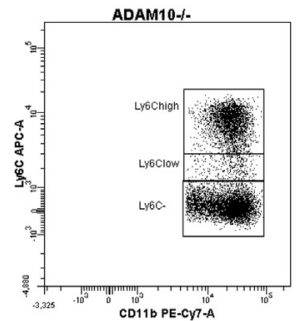

G

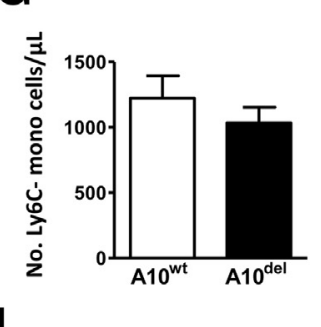

$\mathbf{L}$
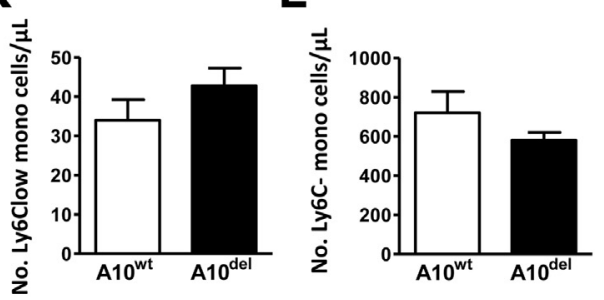

Figure 3 Representative fluorescence-activated cell sorting plots showing granulocyte (Granul) and monocyte (Mono) (sub)populations (A and B) and absolute numbers of circulating Ly6G $\mathrm{G}^{+}$granulocytes $(\mathbf{C}$ and $\mathbf{H})$, Ly6C $\mathrm{C}^{+}$monocytes $(\mathbf{D}$ and $\mathbf{I})$, Ly6 $\mathrm{C}^{\text {high }}$ inflammatory monocytes $(\mathbf{E}$ and $\mathbf{J})$, Ly6 $\mathrm{C}^{\text {low }}$ monocytes $(\mathbf{F}$ and $\mathbf{K})$, and Ly6C-patrolling monocytes $(\mathbf{G}$ and $\mathbf{L})$ in blood of ADAM10 ${ }^{\text {wt }}\left(\mathrm{A} 10^{\text {wt }}\right)$ and ADAM10 $0^{\text {del }}\left(\mathrm{A} 10^{\text {del }}\right)$ transplanted $L d l r^{-/-}$mice at $t=0$ weeks $(\mathbf{C}-\mathbf{G})$ or $t=10$ weeks $(\mathbf{H}-\mathbf{L})$ of Western-type diet feeding. $n=10$ per group. ${ }^{*} P<0.05,{ }^{*} P<0.01$. Ctrl, control.

(Bio-Rad). Quantitative PCR was performed using $10 \mathrm{ng}$ cDNA, $300 \mathrm{nmol} / \mathrm{L}$ of each primer, and SensiMix (Quantace-Bioline, London, UK) in a total volume of $20 \mu \mathrm{L}$. All gene expression levels were corrected for cyclophilin A, $\beta$-actin, and GAPDH as housekeeping genes. Primer sequences are listed in Table 2.

\section{Chemotaxis and Transmigration Assays}

For chemotaxis and transmigration experiments, 24-well Costar transwell chambers (Corning Inc., Corning, NY) were used with $8-\mu \mathrm{m}$ pore-size polycarbonate membranes. For transmigration, membranes were coated with rat tail collagen type I (Millipore, Amsterdam, the Netherlands). Upper wells were filled with $100 \mu \mathrm{L}$ of cell suspension $\left(2 \times 10^{5}\right.$ BMDMs in $100 \mu \mathrm{L}$ RPMI 1640 medium $/ 0.2 \%$ bovine serum albumin). Lower wells contained $600 \mu \mathrm{L} \mathrm{RPMI}$ 1640 medium $/ 0.2 \%$ bovine serum albumin with $3 \mathrm{nmol} / \mathrm{L}$ murine monocyte chemoattractant protein-1. After incubation for 2 hours (chemotaxis) or 4 hours (transmigration), migrated cells were quantified. Migrated cells were lysed with $0.05 \%$ Triton X-100 in phosphate-buffered saline, and endogenous $\beta$-glucuronidase activity was measured using 5 $\mu \mathrm{mol} / \mathrm{L}$ p-nitropheny- $\beta$-D-glucuronide (Calbiochem, San Diego, CA) as a substrate. The number of transmigrated cells was determined using a serially diluted standard of defined cell number run in parallel. After 24 hours, analysis was performed using a microplate reader at $405 \mathrm{~nm}$.

\section{Gelatin Zymography}

Matrix metalloproteinase (MMP)-2 enzymatic activity in ADAM10 ${ }^{\text {wt }}$ and ADAM10 ${ }^{\text {del }}$ BMDM was determined by SDS-PAGE gelatin zymography. Cells were washed twice with phosphate-buffered saline and lysed in ice-cold NP-40 lysis buffer $[50 \mathrm{nmol} / \mathrm{L}$ Tris- $\mathrm{HCl}(\mathrm{pH} 7.4), 100 \mathrm{mmol} / \mathrm{L}$ $\mathrm{NaCl}, 10 \mathrm{mmol} / \mathrm{L} \mathrm{NaF}, 1 \mathrm{mmol} / \mathrm{L} \mathrm{Na}_{3} \mathrm{PO}_{4}, 10 \%$ glycerol, and $1 \%$ Nonidet P-40]. After 10-minute incubation on ice, lysates were collected and $100 \mu \mathrm{g}$ of protein was applied to $12 \%$ SDS-PAGE containing $0.1 \%(\mathrm{w} / \mathrm{v})$ gelatin (Bio-Rad) in the presence of a nonreducing sample buffer [62.5 mmol/ L Tris- $\mathrm{HCl}$ (pH 6.8), 10\% SDS, 25\% glycerol, and $0.01 \%$ bromophenol blue]. Gels were incubated with $2.5 \%$ Triton $\mathrm{X}-100$ (Sigma-Aldrich) for 30 minutes at room temperature, and MMP-2 was activated overnight at $37^{\circ} \mathrm{C}$ in a developing buffer containing $50 \mathrm{mmol} / \mathrm{L}$ Tris- $\mathrm{HCl}$ (pH 7.5), 200 $\mathrm{mmol} / \mathrm{L} \mathrm{NaCl}, 5 \mathrm{mmol} / \mathrm{L} \mathrm{CaCl}_{2}$, and $0.02 \% \mathrm{Brij}-35$ (Sigma-Aldrich). Thereafter, the gels were stained overnight at room temperature with PAGE-blue protein staining solution (Fisher Scientific, Amsterdam, the Netherlands) and destained with deionized water to detect proteolysis as a white band on a blue background. 


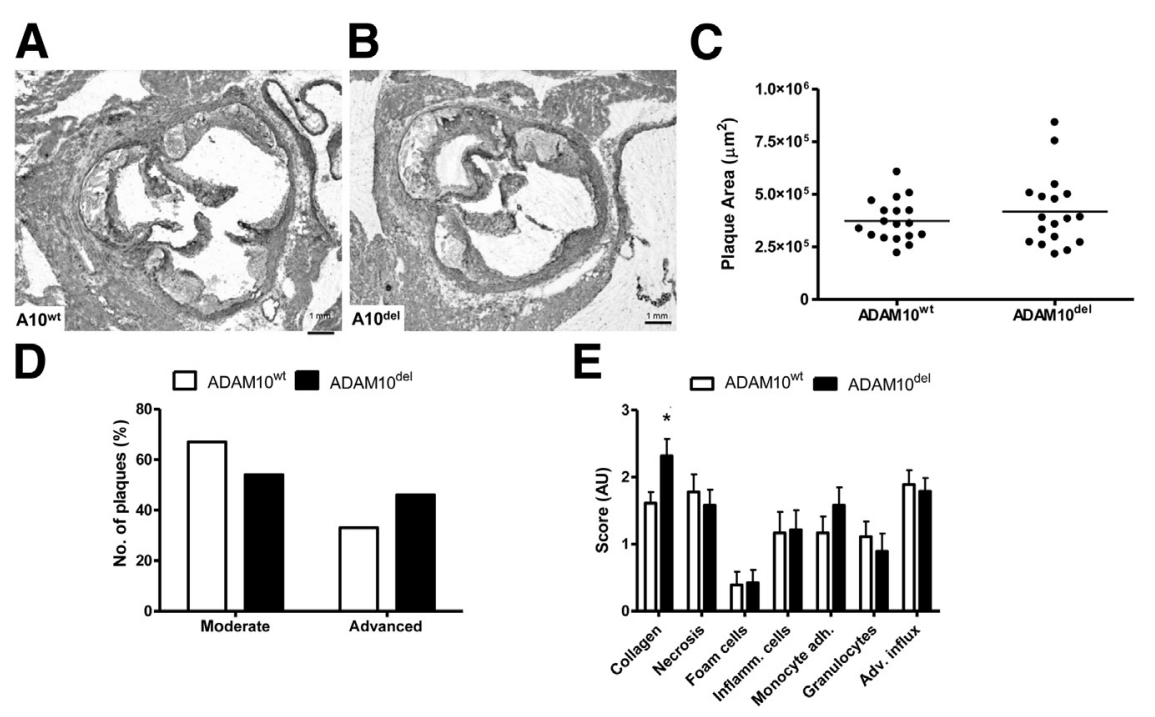

Figure 4 Representative images of toluidine blue-stained sections of the aortic root of $\operatorname{ADAM} 10^{\text {wt }}\left(\mathrm{A} 10^{\mathrm{wt}} ; \mathrm{A}\right)$ and ADAM10 $0^{\mathrm{del}}\left(\mathrm{A} 10^{\mathrm{del}} ; \mathbf{B}\right)$ transplanted mice. Quantification of plaque area (C), plaque classification (D), and routine pathological examination of plaque composition (E). $n=18$ per group. ${ }^{*} P<0.05$. Original magnification, $\times 40(\mathrm{~A}$ and $\mathbf{B})$.

\section{Statistical Analysis}

Data are presented as means \pm SEM. All statistical analyses were performed using the Prism program version 5.01 (GraphPad Software Inc., San Diego, CA). Differences between treatment groups were evaluated for statistical significance with two-tailed, unpaired Student's $t$-test. Significance was accepted at the level of $P<0.05$.

\section{Results}

\section{Generation and Characterization of ADAM10-LysMcre Mice}

To examine the role of myeloid Adam 10 in macrophage functions and atherosclerosis, Adam10 floxed mice ${ }^{11}$ were crossed to mice that express cre under the control of the LysM promoter to drive expression in the myeloid lineage (ie, granulocytes and macrophages). ${ }^{10}$ Adam $10^{f / f}$ LysM-cre ${ }^{+/ 0}$ (ADAM10 ${ }^{\mathrm{del}}$ ) mice were viable and fertile, and no gross abnormalities were found in general organ morphological features at both macroscopic and microscopic levels. Fluorescence-activated cell sorting analyses did not reveal any major effects of myeloid Adam10 deficiency on myeloid or lymphoid cell populations in bone marrow, blood, spleen, and lymph nodes under baseline conditions (data not shown).

Deletion of Adam10 could be confirmed by genomic $\mathrm{PCR}^{17}$ in the myeloid lineage of ADAM10 ${ }^{\mathrm{del}}$ mice (ie, splenic granulocytes, splenic monocytes, and peritoneal macrophages) (Figure 1A). Consistently, Adam10 mRNA expression was significantly reduced in circulating granulocytes, peritoneal and BMDMs, and, to a lesser extent, monocytes, but not in $\mathrm{T}$ cells (Figure 1B). Within the monocyte population, only partial deletion was observed, most likely because LysM expression in circulating monocytes is not sufficient to obtain the Cre levels for recombination and deletion of the floxed gene, as described by Goren et al. ${ }^{18}$ Western blot analysis of BMDM lysates showed expression of inactive
pro-Adam10 (approximately $100 \mathrm{kDa}$ ) and mature, catalytically active Adam10 (approximately $70 \mathrm{kDa}$ ) (Supplemental Figure S2A) in ADAM10 ${ }^{\mathrm{wt}}$. Both forms were significantly reduced in ADAM10 ${ }^{\mathrm{del}}$ BMDMs. In addition, fluorescenceactivated cell sorting analysis of cell surface Adam10 expression (ie, mature Adam10) confirmed this deletion (85\%) (Figure 1C). Moreover, ADAM10 ${ }^{\text {del }}$ BMDMs released significantly $22 \%$ less soluble CXCL16, a known substrate of ADAM10, ${ }^{19}$ indicating loss of Adam10 sheddase function after conditional deletion (Figure 1D). To some extent, the closely related metalloproteinase Adam17, which has partially overlapping substrates, could compensate for the loss of Adam10. However, mRNA expression of Adam17 did not show any compensatory effects in macrophages from ADAM10 ${ }^{\text {del }}$ mice (Supplemental Figure S2B).

\section{Adam10 Deficiency Impairs Macrophage Inflammatory Responses to LPS}

Because macrophages are the main inflammatory cell type in atherosclerotic lesions, regulating the plaque inflammatory milieu by producing various proinflammatory and antiinflammatory mediators, we examined the role of Adam10 in cytokine production by BMDMs after activation by either LPS or oxLDL. Although oxLDL-induced cytokine gene expression was essentially similar between ADAM10 ${ }^{\mathrm{del}}$ and ADAM $10^{\mathrm{wt}}$ BMDMs (data not shown), production of the proinflammatory mediators (Il-12, Tnf, and NO) in response to LPS was reduced in ADAM10 ${ }^{\text {del }}$ BMDMs compared to ADAM10 ${ }^{\text {wt }}$ (Figure 2, A-C). However, anti-inflammatory Il-10 production was increased (Figure 2D). These data may suggest polarization toward alternatively activated macrophages.

\section{Systemic Inflammatory Effects of Myeloid Adam10 Deficiency in $\mathrm{Ldlr}^{-/}$Mice}

Previously, we showed ADAM10 expression associated with human atherosclerotic plaque progression. ${ }^{6}$ However, a 

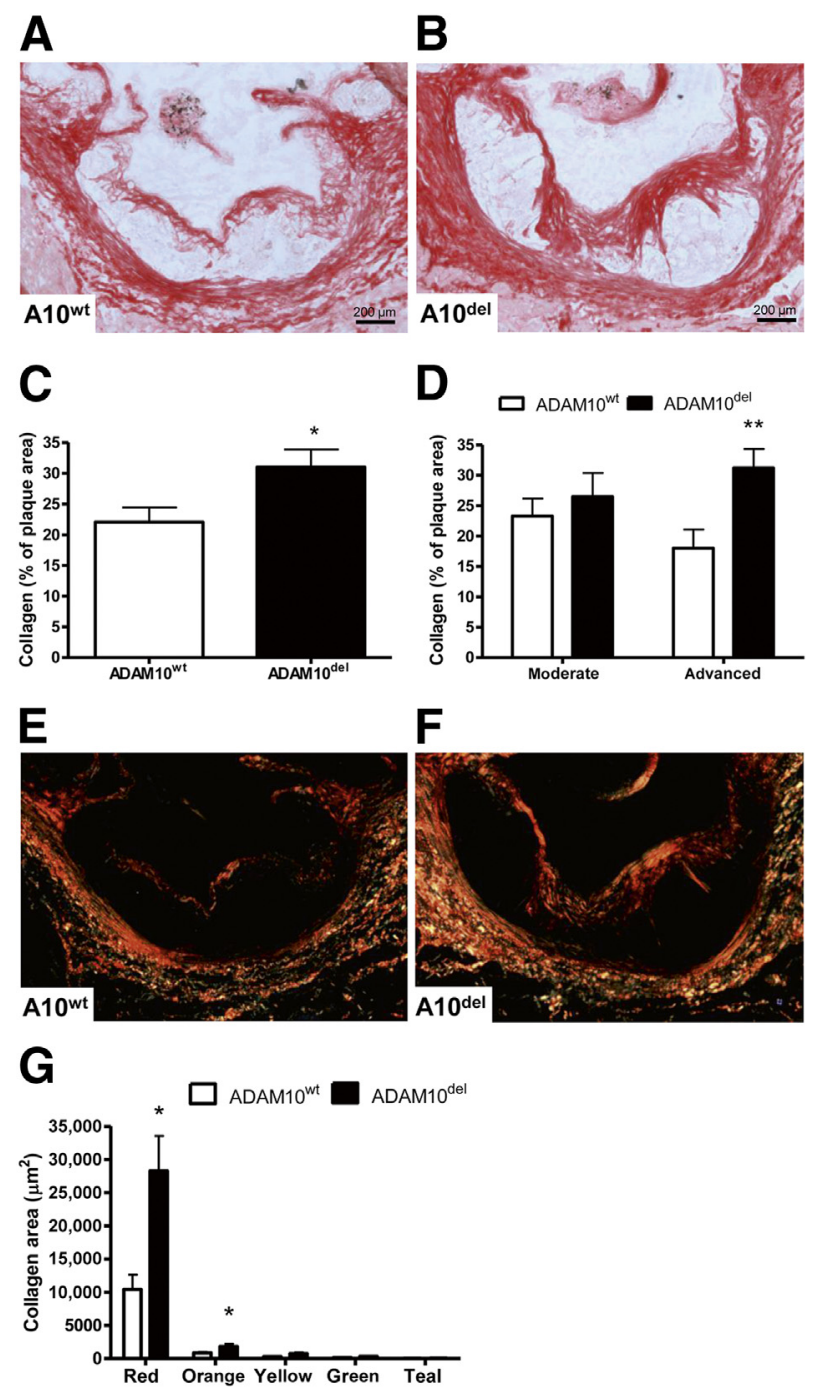

Figure 5 Representative images of Sirius Red-stained collagen, as visualized by normal light microscopy (A and $\mathbf{B})$ and polarizing light microscopy (E and $\mathbf{F}$ ) of ADAM10 $0^{\text {wt }}$ (A10 ${ }^{\text {wt }} ; \mathbf{A}$ and $\left.\mathbf{E}\right)$ and ADAM10 $0^{\text {del }}$ (A10 del; $\mathbf{B}$ and F) transplanted mice. $\mathbf{C}$ and $\mathbf{D}$ : Quantification of total collagen in ADAM10 $0^{\text {wt }}$ and ADAM10 ${ }^{\text {del }}$ transplanted mice. G: Quantification of different collagen fibers in the plaques, ranging from thick, mature collagen (red) to loosely packed, thin collagen fibers (green). $n=15$ to 17 per group ( $\mathbf{C}$ and $\mathbf{D}$ ); $n=9$ to 11 per group $(\mathbf{G}) .{ }^{*} P<0.05,{ }^{* *} P<0.01$. Original magnification: $\times 200(\mathbf{A}$ and $\mathbf{B}) ; \times 40(\mathbf{E}$ and $\mathbf{F})$.

causal role for ADAM10 in atherosclerosis development has not yet been confirmed. Considering the key role of ADAM10 in regulating various inflammatory processes implicated in atherosclerosis, ${ }^{7}$ its high expression in plaque macrophages, ${ }^{6}$ and its role in modulating macrophage inflammatory responses (Figure 2), we investigated the effect of myeloid deficiency of Adam10 on atherosclerosis development. Therefore, we reconstituted lethally irradiated $\mathrm{Ldlr}^{-1-}$ mice with bone marrow from ADAM $10^{\text {del }}$ mice or their wild-type littermate controls (ADAM10 ${ }^{\mathrm{wt}}$ ). Five weeks after reconstitution, mice were given a WTD for 10 weeks, after which atherosclerosis development was assessed in the aortic root. Overall chimerism determination showed 96\% repopulation for both genotypes. No differences between groups were found in body weight $(21.6 \pm 0.4 \mathrm{~g}$ for ADAM10 $^{\mathrm{wt}}$ versus $21.5 \pm 0.5 \mathrm{~g}$ for ADAM10 $0^{\text {del }}$ transplanted mice). Plasma levels of soluble Il-6r, a well-known in vivo substrate for ADAM10, albeit not myeloid specific, ${ }^{20}$ appeared to be $13 \%$ reduced in ADAM10 ${ }^{\text {del }}$ transplanted mice, confirming functional Adam10 deletion in these transplanted animals (Supplemental Figure S3A).

Plasma cholesterol levels before or after feeding a WTD were not different between ADAM10 $0^{\text {del }}$ and ADAM10 $10^{\text {wt }}$ transplanted mice. Triglyceride levels were reduced in ADAM $10^{\text {del }}$ transplanted mice before and after 5 weeks of WTD feeding (25\% and 37\%, respectively), whereas no significant differences were found after 10 weeks of WTD, when mice were sacrificed and atherosclerotic lesions were examined (Supplemental Figure S3, B and C).

Next, we analyzed by flow cytometry circulating leukocyte subset patterns in ADAM10 $0^{\mathrm{del}}$ and ADAM10 ${ }^{\mathrm{wt}}$ transplanted animals after 0,5 , and 10 weeks of WTD. Although total leukocyte numbers, including both lymphoid and myeloid lineages, decreased between 0 and 5 to 10 weeks of WTD, which might be partly due to repopulation dynamics after transplantation, we found no differences in number of total $\mathrm{CD}_{4} 5^{+}$leukocytes or lymphoid lineages between genotypes (data not shown). Interestingly, the number of Ly $6 \mathrm{G}^{+} \mathrm{CD} 11 \mathrm{~b}^{+}$granulocytes was significantly decreased in ADAM $10^{\text {del }}$ transplanted mice, at both baseline and after 10 weeks of WTD feeding (26\% and 21\%, respectively) (Figure 3, A-C and $\mathrm{H}$ ). Although the total number of Ly6 $\mathrm{G}^{-} \mathrm{CD} 11 \mathrm{~b}^{+}$monocytes was not different, analysis of monocyte subsets revealed that the relative amount of Ly6C ${ }^{\text {hi }}$ (inflammatory) monocytes was significantly increased in ADAM10 ${ }^{\text {del }}$ transplanted mice, both at 5 and 10 weeks of WTD feeding (20\% and $26 \%$, respectively) (Figure 3, D-G and I-L, and Supplemental Figure S4). Tissue resident macrophages in the peritoneum, however, did not reflect a more proinflammatory phenotype and even tended to display increased production of anti-inflammatory Il-10 cytokine (Supplemental Figure S5), as also described above for BMDMs (Figure 2D).

\section{Myeloid Deficiency of Adam10 Does Not Affect} Atherosclerotic Lesion Size, but Increases Features of Plaque Stability in $\mathrm{Ldlr}^{-/-}$Mice

Analysis of atherosclerotic lesions in the aortic root revealed no differences in lesion area (Figure 4, A-C) nor in lesion progression between ADAM10 ${ }^{\mathrm{del}}$ and ADAM10 ${ }^{\mathrm{wt}}$ transplanted mice (Figure 4D). Atherosclerotic lesions were further examined by routine pathological examination for their composition (ie, collagen content, necrosis, foam cell content, and amount of inflammatory cells). Although plaque necrosis and foam cell content as well as adventitial inflammatory cell content did not differ between groups, a significant increase in plaque fibrosis was found $(P<0.05)$ (Figure 4E). This increase in plaque fibrosis, observed by routine pathological examination, was quantified by Sirius 
A

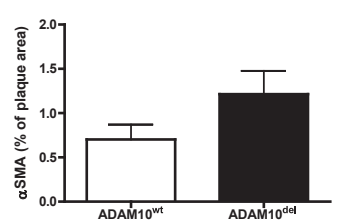

D

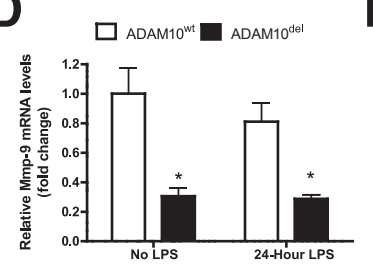

B

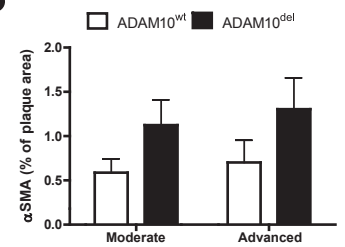

E

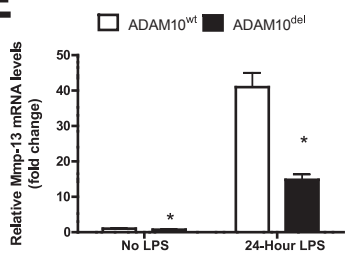

C

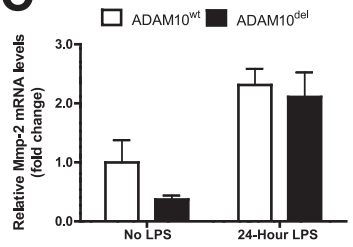

$\mathbf{F}$

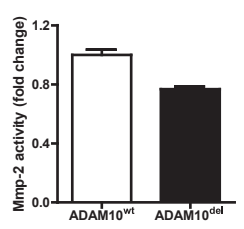

Figure $6 \quad$ A and B: Quantification of $\alpha$-smooth muscle actin $\left(\alpha S M A^{+}\right)$positive smooth muscle cells of ADAM $10^{\text {wt }}$ and ADAM $10^{\text {del }}$ transplanted mice. Matrix metalloproteinase (Mmp)-2 (C), Mmp9 (D), and Mmp-13 (E) mRNA expression in ADAM10 ${ }^{\text {wt }}$ and ADAM10 del of bone marrowderived macrophages (BMDMs) after 24-hour stimulation with 0 to $10 \mathrm{ng} / \mathrm{mL}$ lipopolysaccharide (LPS) in vitro. F: Quantification of $\mathrm{Mmp}-2$ gelatinase activity of BMDMs. $n=12$ to 16 per group (A and $\mathbf{B}) ; n=3$ per group (C-E); $n=2$ (F). ${ }^{*} P<0.05$
Red staining and showed a marked $40.5 \%$ increase in collagen content of ADAM10 ${ }^{\text {del }}$ transplanted mice compared to ADAM10 ${ }^{\mathrm{wt}}(P<0.05)$ (Figure 5, A-D). This effect appeared to be predominantly attributed to an increased collagen content in advanced atherosclerotic lesions $(P<0.01)$ (Figure 5D). Differentiating on the basis of collagen structure (loosely patched, immature, thin collagen versus tightly packed, mature, thick collagen fibers) by using a polarization filter, we were able to demonstrate that increased plaque fibrosis in ADAM10 transplanted mice was due to an increase in mature, thick collagen fiber content $(P<0.05)$ (Figure 5, E-G).

Increased plaque collagen can be the result of either increased production or decreased degradation of collagen. Quantitative real-time PCR analyses revealed that genes associated with collagen production (eg, $T g f b$, collagen I, or arginase I) did not differ between ADAM10 ${ }^{\text {del }}$ and ADAM10 ${ }^{\mathrm{wt}}$ BMDMs (Supplemental Figure S6). To examine whether myeloid Adam10 deficiency could modulate collagen production by vascular SMCs via a paracrine mechanism, we incubated SMCs with conditioned medium of ADAM10 $10^{\text {del }}$ compared to ADAM10 ${ }^{\mathrm{wt}}$ BMDMs. Collagen I, III, IV, or VIII gene expression (Supplemental Figure S7, A-D) as well as collagen synthesis (Supplemental Figure S7E) by SMCs incubated with conditioned medium of ADAM10 ${ }^{\text {del }}$ and ADAM10 ${ }^{\mathrm{wt}}$ BMDMs were essentially similar. Although stimulation of collagen production by SMCs seems not affected, myeloid Adam10 deficiency may influence the amount of SMCs recruited to the atherosclerotic lesions. Quantification of $\alpha$-smooth muscle actin-positive SMCs showed an increase in SMC content in ADAM10 ${ }^{\mathrm{del}}$ plaques, although this difference was not statistically significant (Figure 6, A and B). Regarding collagen degradation, SMCs incubated with conditioned medium did not show any differences in expression of matrix-degrading enzymes (Supplemental Figure S7, F-H), whereas mRNA expression of Mmp-2, Mmp-9, and Mmp-13 in ADAM10 ${ }^{\text {del }}$ BMDMs was reduced $(65 \%, 70 \%$, and $25 \%$, respectively, in non-LPSstimulated cells, which was significant for Mmp-9 and Mmp13) (Figure 6, C-E). To confirm the reduced Mmp gene expression was accompanied by a reduction in matrixdegrading activity, we performed gelatin zymography on BMDM lysates. Although activity levels were low in these cells and even undetectable for Mmp-9, ADAM10 ${ }^{\text {del }}$ BMDMs showed 25\% reduced Mmp-2 gelatinase activity (Figure 6F). In summary, the increase in plaque fibrosis in ADAM10 $10^{\text {del }}$ mice most likely results from a combination of increased SMC numbers and decreased matrix degradation.

To quantify differences in inflammatory cell content of the plaques, immunohistochemical staining was performed. Despite lowered circulating granulocyte levels, no differences were found in the amount of $\mathrm{NIMP}^{+}$plaque neutrophils (Figure $7, \mathrm{~A}-\mathrm{D}$ ). Although relative Moma2 ${ }^{+}$ macrophage content in moderate atherosclerotic lesions was not different, advanced atherosclerotic lesions of ADAM10 ${ }^{\text {del }}$ transplanted mice contained fewer macrophages compared to ADAM10 ${ }^{\mathrm{wt}}$ transplanted mice $(P<0.05)$ (Figure $7, \mathrm{E}-\mathrm{H})$. Because inflammatory cytokine production by ADAM10 ${ }^{\mathrm{del}} \mathrm{BMDMs}$ in response to LPS suggested a more anti-inflammatory alternatively activated phenotype, we quantified inducible nitric oxide synthetase-positive (M1) and Dectin $1^{+}$(M2) macrophages but found no differences (Supplemental Figure S8).

The amount of macrophages in the plaque is determined by the balance between recruitment and cell death. The relative apoptotic cell content in advanced plaques (number of TUNEL $^{+}$cells per plaque area) was significantly decreased in ADAM10 $10^{\text {del }}$ transplanted mice compared to ADAM $10^{\mathrm{wt}}(38 \%, P<0.05)$ (Supplemental Figure S9, A and $\mathrm{B}$ ); however, the number of $\mathrm{TUNEL}^{+}$cells per macrophage area did not change (data not shown), suggesting that the decreased $\mathrm{TUNEL}^{+}$cell content was merely a reflection of the decreased macrophage content. Furthermore, necrotic core content of the atherosclerotic lesions did not differ between groups (Supplemental Figure S9, C and D). As a measure of macrophage recruitment to the plaque, we determined monocyte adhesion at the luminal side of the lesions, showing a trend toward increased numbers of adherent monocytes in ADAM $10^{\text {del }}$ transplanted mice $(P=0.08)$ (Supplemental 

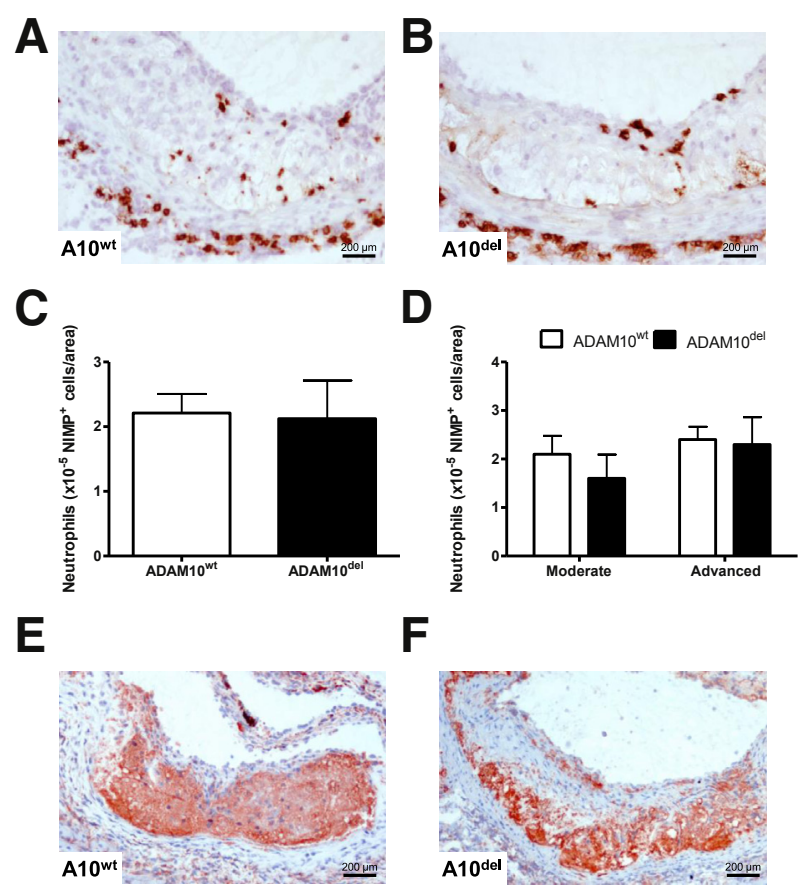

$F$
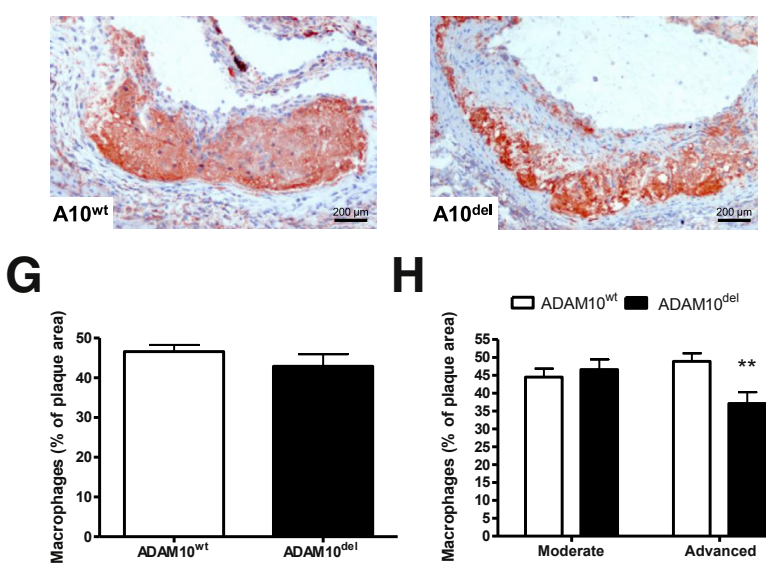

H

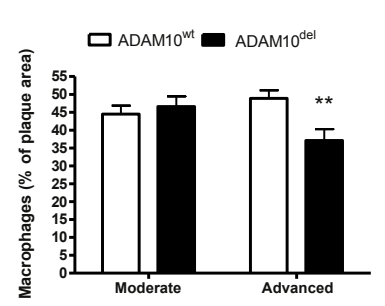

I

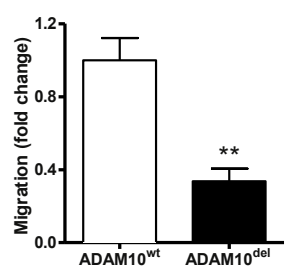

$J$

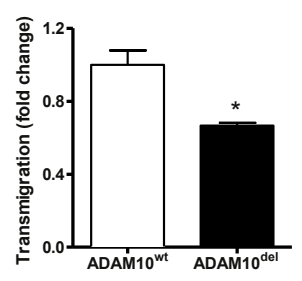

Figure 7 Representative images and quantification of $\mathrm{NIMP}^{+}$neutrophils $(\mathbf{A}-\mathbf{D})$ and $\mathrm{MOMA}^{+}$macrophages $(\mathbf{E}-\mathbf{H})$ of $\mathrm{ADAM} 10^{\mathrm{wt}}\left(\mathrm{A} 10^{\mathrm{wt}}\right)$ and ADAM10 $0^{\text {del }}\left(A 10^{\text {del }}\right.$ ) transplanted mice ( $n=15$ to 17 per group). Monocyte chemoattractant protein-1-induced chemotaxis (I) and transmigration ( $\mathbf{J}$ ) through collagen I of ADAM $10^{\text {wt }}$ and ADAM10 ${ }^{\text {del }}$ bone marrow-derived macrophages. $n=15$ to 17 per group (A-H); $n=3$ per group (I and $\mathbf{J}$ ). ${ }^{*} P<0.05,{ }^{* *} P<0.01$.

Figure S9, E and F). Furthermore, we determined the effect of Adam10 deficiency on macrophage monocyte chemoattractant protein-1-induced chemotaxis and transmigration through collagen type I in vitro. We found both types of migration to be reduced in ADAM10 del BMDMs (Figure 7, I and J). Therefore, the reduced macrophage content in advanced lesions of ADAM10 ${ }^{\mathrm{del}}$ transplanted animals could, at least in part, be explained by a reduced migration capacity of Adam10-deficient macrophages. On the other hand, a reduction in relative macrophage content may be a reflection of the increased fibrosis because the absolute macrophage content was not different (Supplemental Figure S10, A and B).

Altogether, these data indicate that deficiency of Adam 10 dampens macrophage proinflammatory responses and decreases their matrix-degrading and migration capacity in vitro. In vivo, myeloid Adam10 deficiency increased fibrosis and reduced relative macrophage content in the plaque, which suggests enhanced plaque stability.

\section{Discussion}

Herein, we show a causal role of myeloid Adam10 in atherosclerotic plaque development in $\mathrm{Ldlr}^{-1-}$ chimeras. Although myeloid Adam10 deficiency did not affect total plaque size, plaques of myeloid-deficient Adam10 chimeras displayed a more stable phenotype, with apparent increased extracellular matrix content and reduced macrophage accumulation.

\section{Plaque Macrophage Content: Recruitment versus Cell Death}

Conceivably, the reduction in macrophage content in advanced plaques of ADAM10 ${ }^{\text {del }}$ transplanted mice could be explained by a decreased monocyte/macrophage recruitment, because ADAM10 has been implicated in the cleavage of various molecules important for chemotaxis, adhesion, and (trans)migration (eg, cadherins and selectins). ${ }^{21}$ Interestingly, we found an increase in circulating inflammatory Ly6C ${ }^{\text {hi }}$ monocytes in ADAM10 ${ }^{\text {del }}$ transplanted mice, which could indicate a decrease in adhesion and migration to the vessel wall. Monocyte adhesion to the atherosclerotic lesion was not significantly altered between groups, and showed even a trend to increased monocyte adhesion. This modest effect is likely due to the fact that monocytes do not express sufficient lysozyme to obtain effective deletion of the floxed Adam 10 gene. ${ }^{18}$ We found a reduction in macrophage monocyte chemoattractant protein1 -induced migration and transmigration through collagen type I in vitro, which could, at least in part, explain the reduction in macrophage content in advanced lesions of ADAM10 ${ }^{\text {del }}$ transplanted mice. Similarly, we recently demonstrated reduced leukocyte infiltration into acutely inflamed lung in Adam10-LysMcre mice. ${ }^{22}$ Various molecules important for leukocyte recruitment have been shown to be cleaved by Adam10, including cadherins ${ }^{23}$ as well as Cxcl16 and fractalkine, two chemokines (expressed not only in myeloid cells, but also in endothelium) that act as adhesion molecules in their membrane-bound form and chemotactic factors when soluble. ${ }^{24,25}$ These chemokines are especially important in advanced atherosclerotic plaques. ${ }^{26}$ On the other hand, we did not observe a difference in plaque neutrophil numbers in ADAM10 $0^{\text {del }}$ transplanted mice, despite a significant reduction in circulating granulocytes. Considering its role in junctional/adhesion molecule cleavage in endothelial cells, regulating endothelial 
permeability and leukocyte recruitment, it is conceivable that endothelial-specific deletion of ADAM10 would have a stronger effect on atherogenesis.

In addition to reduced macrophage recruitment, the reduced macrophage content in advanced plaques of ADAM $10^{\text {del }}$ transplanted mice could also be caused by increased macrophage apoptosis. Indeed, ADAM10 has been implicated in the shedding of members of the death receptor family (eg, TNF, CD40L, and FasL), ${ }^{27,28}$ and ADAM10 deficiency could, therefore, lead to increased apoptosis. However, the number of $\mathrm{TUNEL}^{+}$cells per macrophage area was even reduced in advanced lesions, indicating that cell death does not explain the differences in macrophage content.

\section{Plaque Fibrosis: A Balance between Collagen Production and Degradation}

Myeloid Adam10 deficiency considerably increased plaque fibrosis in ADAM10 ${ }^{\text {del }}$ transplanted mice, which could be related to the relative decrease in macrophage content. The plaque extracellular matrix content is determined by the balance between collagen production and degradation. Known inducers of collagen production in myeloid cells, especially in the wound-healing (M2) macrophage phenotype,$^{29}$ are, for example, arginase I, Fizz-1, and transforming growth factor $\beta$. Arginase is an enzyme that drives L-arginine metabolism toward ornithine and subsequently proline production, which is critical for collagen synthesis. ${ }^{30}$ Although we did find Adam10-deficient BMDMs to produce fewer proinflammatory mediators, such as Tnf, Il-12, and NO, but more anti-inflammatory cytokine Il-10 in response to LPS, suggesting a switch toward M2 macrophages, we could not find an increase in profibrotic M2 markers, such as arginase I, YM-1, Fizz-1, or transforming growth factor $\beta$. Indeed, ADAM10 ${ }^{\text {del }}$ plaques did not show any differences in inducible nitric oxide synthetasepositive or Dectin- $1^{+}$macrophages, markers of M1 or M2 macrophages, respectively, indicating that the Adam10 deficiency in macrophages does not induce a general switch in polarization. In peritoneal macrophages isolated from the atherosclerotic mice, Adam10 deficiency also resulted in a much milder, although still anti-inflammatory, response to LPS. This, however, does not necessarily reflect the situation in the atherosclerotic lesions, where other stimuli (eg, oxLDL) may be more relevant. TNF is a well-known target of ADAM17 cleavage, although other proteases, including ADAM10, are capable of releasing $\mathrm{TNF}^{27}$ and this may become important under pathological conditions. However, it remains to be determined how Adam10 deletion affects the expression of the other inflammatory mediators. It is conceivable, though, that this is an indirect effect of reduced $\mathrm{Tnf}$ production in Adam10-deficient macrophages (Figure 2B). Moreover, ADAM $10^{\text {del }}$ macrophage-conditioned medium did neither change expression nor production of collagen by vascular SMCs. Hence, the increased plaque fibrosis can probably not be attributed to a stimulated collagen production, although we found an (nonsignificant) increase in SMC content that could contribute to the increase in fibrosis. At the other side of the equation, ADAM $10^{\mathrm{del}}$ macrophages displayed decreased expression of MMPs (eg, Mmp-2, Mmp-9, and Mmp-13) and reduced Mmp-2 gelatinase activity responsible for the degradation of the extracellular matrix. Moreover, Adam10 itself has been reported to have matrix-degrading capacity, albeit in a rather artificial in vitro setting. ${ }^{31}$ Therefore, it is conceivable that the increased collagen content in plaques of ADAM $10^{\text {del }}$ transplanted mice is caused either directly or indirectly by decreased collagenase activity. Whether Adam10 deficiency directly leads to decreased Mmp activity or is an indirect effect [eg, by changing the macrophage phenotype by reducing Tnf- $\alpha$ or integrin signaling (now modulated by the absence of the Adam10 disintegrin domain)] remains to be determined.

In addition to myeloid cells, the role of Adam 10 in other vascular cells (eg, endothelial cells and SMCs) in atherosclerosis can be investigated using other cre-deleter strains.

In conclusion, this study is the first to unveil a causal role of ADAM10 in atherosclerosis. Deletion of Adam10 in the myeloid lineage did not affect plaque size, but increased plaque fibrosis and reduced macrophage accumulation. Consistently, in vitro production of inflammatory mediators, migratory and matrix-degrading capacity of BMDMs, was reduced. By shifting the balance from inflammation toward more fibrosis, myeloid ADAM10 deficiency may enhance plaque stability.

\section{Acknowledgments}

We thank Patrick van Gorp and Chantal Pöttgens for technical support.

E.P.C.v.d.V., M.J., I.M.J.W., and M.M.P.C.D. designed and performed experiments and analyzed the data; M.J., A.K., K.T., E.W., S.W., M.J.G., A.A.J.H., and D.D. performed experiments and analyzed data; L.S., S.R.-J., A.L., and P.S. contributed critical reagents/materials/analysis tools; M.P.J.d.W., E.A.L.B., and M.M.P.C.D. contributed to conception of this manuscript; E.P.C.v.d.V. and M.M.P.C.D. drafted the manuscript; and I.M.J.W., S.W., M.P.J.d.W., A.L., P.S., E.A.L.B., and M.M.P.C.D. revised the manuscript.

\section{Supplemental Data}

Supplemental material for this article can be found at http://dx.doi.org/10.1016/j.ajpath.2014.11.028.

\section{References}

1. Crawford HC, Dempsey PJ, Brown G, Adam L, Moss ML: ADAM10 as a therapeutic target for cancer and inflammation. Curr Pharm Des 2009, 15:2288-2299

2. Duffy MJ, McKiernan E, O'Donovan N, McGowan PM: The role of ADAMs in disease pathophysiology. Clin Chim Acta 2009, 403:31-36

3. Hartmann D, de Strooper B, Serneels L, Craessaerts K, Herreman A, Annaert W, Umans L, Lubke T, Lena Illert A, von Figura K, Saftig P: 
The disintegrin/metalloprotease ADAM 10 is essential for Notch signalling but not for alpha-secretase activity in fibroblasts. Hum Mol Genet 2002, 11:2615-2624

4. Zhang C, Tian L, Chi C, Wu X, Yang X, Han M, Xu T, Zhuang Y, Deng K: Adam10 is essential for early embryonic cardiovascular development. Dev Dyn 2010, 239:2594-2602

5. Glomski K, Monette S, Manova K, De Strooper B, Saftig P, Blobel CP: Deletion of Adam10 in endothelial cells leads to defects in organ-specific vascular structures. Blood 2011, 118:1163-1174

6. Donners MM, Wolfs IM, Olieslagers S, Mohammadi-Motahhari Z, Tchaikovski V, Heeneman S, van Buul JD, Caolo V, Molin DG, Post MJ, Waltenberger J: A disintegrin and metalloprotease 10 is a novel mediator of vascular endothelial growth factor-induced endothelial cell function in angiogenesis and is associated with atherosclerosis. Arterioscler Thromb Vasc Biol 2010, 30:2188-2195

7. van der Vorst EP, Keijbeck AA, de Winther MP, Donners MM: A disintegrin and metalloproteases: molecular scissors in angiogenesis, inflammation and atherosclerosis. Atherosclerosis 2012, 224:302-308

8. Virmani R, Kolodgie FD, Burke AP, Finn AV, Gold HK, Tulenko TN, Wrenn SP, Narula J: Atherosclerotic plaque progression and vulnerability to rupture: angiogenesis as a source of intraplaque hemorrhage. Arterioscler Thromb Vasc Biol 2005, 25:2054-2061

9. Libby P, Ridker PM, Maseri A: Inflammation and atherosclerosis. Circulation 2002, 105:1135-1143

10. Clausen BE, Burkhardt C, Reith W, Renkawitz R, Forster I: Conditional gene targeting in macrophages and granulocytes using LysMcre mice. Transgenic Res 1999, 8:265-277

11. Jorissen E, Prox J, Bernreuther C, Weber S, Schwanbeck R, Serneels L, Snellinx A, Craessaerts K, Thathiah A, Tesseur I, Bartsch U, Weskamp G, Blobel CP, Glatzel M, De Strooper B, Saftig P: The disintegrin/metalloproteinase ADAM10 is essential for the establishment of the brain cortex. J Neurosci 2010, 30:4833-4844

12. Kanters E, Gijbels MJ, van der Made I, Vergouwe MN, Heeringa P, Kraal G, Hofker MH, de Winther MP: Hematopoietic NF-kappaB1 deficiency results in small atherosclerotic lesions with an inflammatory phenotype. Blood 2004, 103:934-940

13. Kanters E, Pasparakis M, Gijbels MJ, Vergouwe MN, PartounsHendriks I, Fijneman RJ, Clausen BE, Forster I, Kockx MM, Rajewsky K, Kraal G, Hofker MH, de Winther MP: Inhibition of NFkappaB activation in macrophages increases atherosclerosis in LDL receptor-deficient mice. J Clin Invest 2003, 112:1176-1185

14. Gijbels MJ, van der Cammen M, van der Laan LJ, Emeis JJ, Havekes LM, Hofker MH, Kraal G: Progression and regression of atherosclerosis in APOE3-Leiden transgenic mice: an immunohistochemical study. Atherosclerosis 1999, 143:15-25

15. MacKenna DA, Omens JH, Covell JW: Left ventricular perimysial collagen fibers uncoil rather than stretch during diastolic filling. Basic Res Cardiol 1996, 91:111-122

16. Rensing KL, de Jager SC, Stroes ES, Vos M, Twickler MT, DallingaThie GM, de Vries CJ, Kuiper J, Bot I, von der Thusen JH: Akt2/LDLr double knockout mice display impaired glucose tolerance and develop more complex atherosclerotic plaques than LDLr knockout mice. Cardiovasc Res 2014, 101:277-287

17. Weber S, Niessen MT, Prox J, Lullmann-Rauch R, Schmitz A, Schwanbeck R, Blobel CP, Jorissen E, de Strooper B, Niessen CM, Saftig P: The disintegrin/metalloproteinase Adam10 is essential for epidermal integrity and Notch-mediated signaling. Development 2011, 138:495-505

18. Goren I, Allmann N, Yogev N, Schurmann C, Linke A, Holdener M, Waisman A, Pfeilschifter J, Frank S: A transgenic mouse model of inducible macrophage depletion: effects of diphtheria toxin-driven lysozyme M-specific cell lineage ablation on wound inflammatory, angiogenic, and contractive processes. Am J Pathol 2009, 175:132-147

19. Ludwig A, Hundhausen C, Lambert MH, Broadway N, Andrews RC, Bickett DM, Leesnitzer MA, Becherer JD: Metalloproteinase inhibitors for the disintegrin-like metalloproteinases ADAM10 and ADAM17 that differentially block constitutive and phorbol esterinducible shedding of cell surface molecules. Comb Chem High Throughput Screen 2005, 8:161-171

20. Garbers C, Janner N, Chalaris A, Moss ML, Floss DM, Meyer D, Koch-Nolte F, Rose-John S, Scheller J: Species specificity of ADAM10 and ADAM17 proteins in interleukin-6 (IL-6) transsignaling and novel role of ADAM10 in inducible IL-6 receptor shedding. J Biol Chem 2011, 286:14804-14811

21. Reiss K, Saftig P: The "a disintegrin and metalloprotease" (ADAM) family of sheddases: physiological and cellular functions. Semin Cell Dev Biol 2009, 20:126-137

22. Pruessmeyer J, Hess FM, Ahlert H, Groth E, Pasqualon T, Schwarz N, Nyamoya S, Kollert J, van der Vorst E, Donners M, Martin C, Uhlig S, Saftig P, Dreymueller D, Ludwig A: Leukocytes require the metalloproteinase ADAM10 but not ADAM17 for cell migration and for inflammatory leukocyte recruitment into the alveolar space. Blood 2014, 123: 4077-4088

23. Reiss K, Maretzky T, Ludwig A, Tousseyn T, de Strooper B, Hartmann D, Saftig P: ADAM10 cleavage of N-cadherin and regulation of cell-cell adhesion and beta-catenin nuclear signalling. EMBO J 2005, 24:742-752

24. Hundhausen C, Schulte A, Schulz B, Andrzejewski MG, Schwarz N, von Hundelshausen P, Winter U, Paliga K, Reiss K, Saftig P, Weber C, Ludwig A: Regulated shedding of transmembrane chemokines by the disintegrin and metalloproteinase 10 facilitates detachment of adherent leukocytes. J Immunol 2007, 178:8064-8072

25. Ludwig A, Weber C: Transmembrane chemokines: versatile "special agents" in vascular inflammation. Thromb Haemost 2007, 97:694-703

26. Cheng C, Tempel D, van Haperen R, de Boer HC, Segers D, Huisman M, van Zonneveld AJ, Leenen PJ, van der Steen A, Serruys PW, de Crom R, Krams R: Shear stress-induced changes in atherosclerotic plaque composition are modulated by chemokines. J Clin Invest 2007, 117:616-626

27. Hikita A, Tanaka N, Yamane S, Ikeda Y, Furukawa H, Tohma S, Suzuki R, Tanaka S, Mitomi H, Fukui N: Involvement of a disintegrin and metalloproteinase 10 and 17 in shedding of tumor necrosis factoralpha. Biochem Cell Biol 2009, 87:581-593

28. Schulte M, Reiss K, Lettau M, Maretzky T, Ludwig A, Hartmann D, de Strooper B, Janssen O, Saftig P: ADAM10 regulates FasL cell surface expression and modulates FasL-induced cytotoxicity and activation-induced cell death. Cell Death Differ 2007, 14: $1040-1049$

29. Wolfs IM, Donners MM, de Winther MP: Differentiation factors and cytokines in the atherosclerotic plaque micro-environment as a trigger for macrophage polarisation. Thromb Haemost 2011, 106:763-771

30. Raes G, Van den Bergh R, De Baetselier P, Ghassabeh GH, Scotton C, Locati M, Mantovani A, Sozzani S: Arginase-1 and Ym1 are markers for murine, but not human, alternatively activated myeloid cells. J Immunol 2005, 174:6561; author reply 6561-6562

31. Millichip MI, Dallas DJ, Wu E, Dale S, McKie N: The metallodisintegrin ADAM10 (MADM) from bovine kidney has type IV collagenase activity in vitro. Biochem Biophys Res Commun 1998, 245:594-598 